\title{
ALFABETIZAÇÃO CIENTÍFICA NO CONTEXTO DE PESQUISAS ACADÊMICAS EM ENSINO DE CIÊNCIAS
}

\section{ESTADO DO CONHECIMENTO}

MATHEUS, Ilda Felix ${ }^{1}$

MACIEL, Maria Delourdes ${ }^{2}$

MATHEUS, Ilda Felix; MACIEL, Maria Delourdes. Alfabetização científica no contexto de pesquisas acadêmicas em ensino de ciências. Revista Científica Multidisciplinar Núcleo do Conhecimento. Ano 04, Ed. 03, Vol. 02, pp. 05-22. Março de 2019. ISSN: 2448-0959.

\section{RESUMO}

Nas últimas décadas, o Ensino de Ciências tem se constituído por produções científicas que provocaram mudanças na sociedade. $O$ avanço das tecnologias e suas inovações trouxeram conhecimentos que alteraram o modo como vivem os cidadãos em seu grupo social. A Alfabetização Científica favorece o entendimento e a compreensão do conhecimento das Ciências Naturais e da Tecnologia auxiliando o estudante na contextualização dos conteúdos científicos propostos no enfoque Ciência/Tecnologia/Sociedade (CTS). Este estudo tem como objetivo identificar em

\footnotetext{
${ }_{1}^{1}$ Mestranda em Ensino de Ciências, Pós graduanda em Educação em Saúde Pública e em Formação Docente para o Ensino Superior, graduada em Ciências Biológicas e em Pedagogia, Estudante.

${ }^{2}$ Graduação em Ciências Biológicas pela Universidade Federal do Rio Grande do Sul (1976); Mestrado em Educação (Supervisão e Currículo) pela Pontifícia Universidade Católica de São Paulo (1995); Doutorado em Educação (Psicologia da Educação) pela Pontifícia Universidade Católica de São Paulo (2001); Pós-doutorado em Educação pela Pontifícia Universidade Católica de São Paulo (2006), Professora Titular III na Universidade Cruzeiro do Sul.
} 
Dissertações de Mestrado dos Programas de Ensino de Ciências, quais metodologias e instrumentos de coleta de dados foram utilizadas por outros pesquisadores a fim de identificar a ocorrência de Alfabetização Científica na Educação Básica e no Ensino Superior. A pesquisa ocorreu em dissertações produzidas em cursos brasileiros de pós-graduação, no período de 2013 a 2107, do tipo estado do conhecimento. Para a organização e análise de dados recorremos à Análise de conteúdo. O estudo demostrou que a escolha das metodologias apoiaram-se nos objetivos contidos nas dissertações e seus autores buscaram, na coleta de dados, o entendimento da Alfabetização Científica, ou seja, como tema promove o empoderamento científico nos estudantes, independentemente da etapa educacional em que se encontram, potencializando suas habilidades de leitura, significação e compreensão do seu cotidiano, fazendo conexões com outras áreas do conhecimento.

Palavras-chave: Ensino de Ciências, Alfabetização Cientifica, Ciências/Tecnologia/Sociedade (CTS), Mapeamento.

\section{INTRODUÇÃO}

O movimento Ciências/Tecnologia/Sociedade (CTS) propicia ao estudante reconhecer-se no mundo, favorecendo as descobertas por meio de reflexões e discussões que possibilitem o desenvolvimento de habilidades de leitura e de investigação, contemplando as decisões de ocorrências no meio social do qual faz parte (CUNHA, 2006). Para tanto, o educando deve ser capaz de estabelecer relações entre conhecimentos científicos que estão para além dos conteúdos trabalhados em sala de aula; perceber a dimensão social da Ciência e da Tecnologia; compreender esta dimensão social tanto no que diz respeito aos seus aspectos históricos, políticos, econômicos e sociais, quanto às suas consequências ambientais e sociais (VIEIRA; MARTINS, 2009).

Nas últimas décadas, o Ensino de Ciências como disciplina tem sido constituído pelas produções científicas que compeliram as mudanças ocorridas nas sociedades. Do mesmo modo, os avanços das tecnologias e suas inovações trouxeram conhecimentos que alteraram o modo como vivem os cidadãos em seu grupo social 
(KRASILCHIK, 2000). Porém, sabe-se que apenas uma pequena parcela da população tem acesso ao conhecimento produzido pelos meios científicos. Neste caso, pensamos a escola como um espaço para promover a cultura científica, podendo proporcionar a enculturação científica dos alunos, levando recursos para que sejam inseridos em mais uma cultura, a cultura científica (SASSERON; CARVALHO, 2011).

As questões científicas precisam ser discutidas na formação de indivíduos, tendo em vista o despertar de sua criatividade, criticidade, autonomia, capacidade argumentativa, visando a possibilidade da interpretação e compreensão das mudanças no mundo postas pela ciência e tecnologia e também seu meio social. Já os documentos oficiais, como os Parâmetros Curriculares Nacionais (PCN), revelam que, na década de 1980, com o crescimento industrial e suas consequências para o meio ambiente e a saúde da população, houve na Educação Básica a abertura da tendência Ciência/Tecnologia/Sociedade (CTS). As discussões sobre os efeitos do crescimento industrial deram início às mudanças curriculares nas áreas das Ciências Naturais. Em 1998, os PCN trouxeram a proposta de mudança e a tendência Ciência/Tecnologia/Sociedade (CTS), a qual se tornou um parâmetro para os currículos da disciplina de ciências, organizando-se, assim, de forma interdisciplinar, o que representou um desafio para as práticas pedagógicas da área (BRASIL, 1998).

Segundo Lopes et. al (2017), o enfoque CTS pode ser um facilitador da Alfabetização Científica (AC), por favorecer o entendimento e a compreensão do conhecimento das Ciências Naturais e da Tecnologia. Desta forma, o estudante, na contextualização dos conteúdos científicos propostos no enfoque CTS, pode ajustar-se às mudanças ocorridas na natureza e no meio social, a partir do seu interesse e participação efetiva na sociedade da qual faz parte.

Neste contexto, o objetivo desta pesquisa foi analisar Dissertações de Mestrado de Programas de Ensino de Ciências, a fim de identificar quais metodologias e instrumentos de coletas de dados foram utilizadas pelos pesquisadores e verificar a ocorrência de AC na Educação Básica e Ensino Superior. Para alcançar tais objetivos, o presente estudo caracteriza-se como uma pesquisa do tipo estado do conhecimento, 
em que foram mapeadas dissertações publicadas em âmbito nacional no período de 2013 a 2017.

\section{O ENSINO DE CIÊNCIAS E SUAS CONTRIBUIÇÕES NO PROCESSO DE ALFABETIZAÇÃO CIENTÍFICA}

Nas últimas décadas, o Ensino de Ciências experimentou alterações impulsionadas pelos avanços tecnológicos, que alteraram o modo como vivem os cidadãos em seu grupo social. Neste sentido, a Educação Escolar teve que transformar o modo como o conhecimento era transmitido; introduzir mudanças nos currículos norteados por documentos oficiais impostos pela nova demanda da criança/educando contemporânea, que, ao adentrarem nas Instituições Educacionais, trouxeram conhecimentos ofertados por outros espaços de aprendizagem, com todos os aparatos tecnológicos ofertados neste século (CARVALHO, 2013).

O Ensino de Ciências no Brasil é relativamente novo para todos os níveis de ensino, já que a disciplina só se estabeleceu nas escolas de educação básica a partir da Lei no 5.692/1971. Até então, Ciências era ministrada nas duas últimas séries do 1 Grau, atual Ensino Fundamental (TRIVELATO; SILVA, 2011). Entretanto, o conteúdo era organizado segundo as orientações das secretarias estaduais, não tendo o professor autonomia para sistematizar o conhecimento, adequando-o à realidade dos educandos. Os professores eram transmissores de conhecimento e os alunos meros receptores. Não havia qualquer preocupação com os conhecimentos prévios dos estudantes (BRASIL, 1997).

Outro ponto que devemos ressaltar é que a Ciência é uma produção social na qual as transformações ocorridas ao longo do tempo são processos de produção do conhecimento, respondendo ao cenário do crescimento global (TRIVELATO; SILVA, 2011). Nesta perspectiva, "a escola, com a finalidade de levar os alunos da geração atual a conhecer o que já foi historicamente produzido pelas gerações anteriores, também foi atingida por tais mudanças sociais" (CARVALHO, 2011, p. 1). 
Krasilchik (2000) considera que o Ensino de Ciências sofreu modificações, tanto em nível nacional como internacional:

Na história do ensino de Ciências, que influi até hoje nas tendências curriculares das várias disciplinas tanto no ensino médio como no fundamental, foi dando lugar, ao longo dessas últimas décadas, a outras modificações em função de fatores políticos, econômicos e sociais que resultaram, por sua vez, em transformações das políticas educacionais, cumulativas em função das quais ocorreram mudanças no ensino de Ciências (KRASILCHIK, 2000, p. 85-86).

Um estudo de Trivelato e Silva (2011) destaca que as mudanças significativas ocorridas ao longo do percurso do ensino de Ciências ainda não atendem à formação crítica do educando, embora apresentem uma possibilidade de ação dialógica em sala de aula. Neste sentido, as autoras ressaltam:

Na segunda metade do século passado, o modelo desenvolvimentista adotado, com base na industrialização acelerada, gerou sérios problemas sociais e ambientais. Os problemas relativos ao meio ambiente e à saúde começaram a aparecer nos currículos de ciências, embora abordados em diferentes níveis de profundidade. A partir dos anos 1980, a tendência conhecida como 'Ciências, Tecnologia, Sociedade' (CTS) também passou a ser incorporada ao ensino de Ciências. (TRIVILATO; SILVA, 2011, p. 4).

Entende-se por enfoque CTS na educação, as interações estabelecidas pela tríade Ciência, Tecnologia e Sociedade. Trazer essas relações CTS para a sala de aula significa trabalhar com os conteúdos científicos e ou tecnológicos de modo que os estudantes possam integrar esses conhecimentos com suas experiências do dia a dia (SANTOS; AMARAL; MACIEL, 2010). 
Segundo Silva e Albrech (2010), estas interações provocam um repensar por parte dos profissionais da Educação diante dos desafios relacionados às questões do currículo, do ensino e da formação de professores.

Soligo, Maciel e Guazzelli (2010) enfatizam que:

O enfoque CTS defende que a escola, assim como outros espaços educativos, deve assumir o compromisso com uma didática das Ciências voltada para discutir as questões científico-tecnológicas que afetam a vida das pessoas, a vida em sociedade e as relações com o meio, tendo em vista a alfabetização científica para a cidadania. (SOLIGO, MACIEL; GUAZZELLI, 2010, p. 123).

Atualmente, ensinar Ciências deve suplantar a mera transmissão de conceitos, teorias, leis, de modo a preparar os educandos para refletirem sobre o processo de produção científica e a apreensão do conhecimento científico acumulado.

Nos documentos oficiais, como a Lei de Diretrizes e Bases da Educação NacionalLDBEN (BRASIL, 1996), os Parâmetros Curriculares Nacionais (PCN) (BRASIL, 1997) e a Base Nacional Comum Curricular (BNCC) (BRASIL, 2017) propõem um ensino com metodologias diversificadas, despertando no educando a motivação e a disposição pelo conhecimento científico. Desta forma, cabe à escola repensar o Ensino de Ciências e sua relevância, visto que os PCN pleiteiam uma formação integral em que os estudantes sejam alfabetizados cientificamente para que possam compreender na Educação Básica as vantagens e desvantagens do uso das tecnologias no contexto social, ou seja:

Pela abrangência e pela natureza dos objetos de estudo das Ciências, é possível desenvolver a área de forma muito dinâmica, orientando o trabalho escolar para o conhecimento sobre fenômenos da natureza, incluindo o ser humano e as tecnologias mais próximas e mais distantes, no espaço e no tempo. Estabelecer relações entre o que é conhecido e as novas ideias, entre o comum e o diferente, entre o particular e o geral, 
definir contrapontos entre os muitos elementos no universo de conhecimentos são processos essenciais à estruturação do pensamento, particularmente do pensamento científico. (BRASIL, 1997, p. 27).

A BNCC, de 2017, documento estabelecido pela LDB, de 1996, já defendido nos anos 1980, explicita que os currículos escolares do país necessitavam de uma base comum, pela diversidade cultural das regiões do país. Este documento tem como objetivo orientar as diversas áreas do conhecimento das unidades educacionais do Brasil, na Educação Básica, norteando o processo de ensino e aprendizagem, atuando como referência nas fases de formação de crianças e jovens. A proposta do documento é servir de elemento norteador na construção do conhecimento, considerando que cada região tem suas características sociais, físicas e biológicas.

No que diz respeito ao Ensino de Ciências da Natureza, outras questões tratadas na Base Nacional Comum Curricular (BNCC) envolvem ética, política e cultura científica:

Ao longo do Ensino Fundamental, a área de Ciências da Natureza tem um compromisso com o desenvolvimento do letramento científico, que envolve a capacidade de compreender e interpretar o mundo (natural, social e tecnológico), mas também de transformá-lo com base nos aportes teóricos e processuais da ciência. (BRASIL, 2017, p. 273).

Qual seria, então, o papel da escola e do ensino de Ciências da Natureza? Estes questionamentos são importantes, no quesito responsabilidade das Unidades Educacionais, para o favorecimento da cultura científica. Segundo Viecheneski e Carletto (2011), a aquisição do conhecimento científico é precípua ao estudante e essencial a sua educação formal, ou seja, alicerçado nos sistemas de ensino, é necessário à formação dos cidadãos que vivem em sociedades em constante crescimento e transformação, impelidas pela ciência e tecnologia. 
Nesta mesma linha, Chassot (2016) faz as seguintes indagações: por que ensinar Ciências? Ou, por que ensinar? Por que (re)temos os educandos por tanto tempo na escola? Para responder a essas questões, o autor propõe:

A nossa responsabilidade maior no ensinar Ciências é procurar que nossos alunos e alunas se transformem, com o ensino que fazemos, em homens e mulheres mais críticos. Sonhamos que, com o nosso fazer educação, os estudantes possam tornar-se agentes de transformações - para melhor - do mundo em que vivemos. (CHASSOT, 2016, p. 63).

Como já mencionado, o progresso científico e tecnológico das últimas décadas dos séculos XX e XXI estão postos no hoje. Questionamos: como seduzir os estudantes para o empoderamento da cultura científica de tal forma que suas ações possam refletir no bem comum, como preconiza Chassot (2016)? A escola tem papel importante neste empoderamento da cultura científica, sobretudo em aulas de Ciências, como propõe Sasseron e Carvalho:

Os autores brasileiros que usam a expressão 'Enculturação Científica' partem do pressuposto de que o ensino de Ciências pode e deve promover condições para que os alunos, além das culturas religiosa, social e histórica que carregam consigo, possam também fazer parte de uma cultura em que as noções, ideias e conceitos científicos são parte de seu corpus. Deste modo, seriam capazes de participar das discussões desta cultura, obtendo informações e fazendo-se comunicar (SASSERON; CARVALHO, 2011, p. 60).

Para alguns pesquisadores, o termo Letramento Científico aproxima-se da expressão Letramento em Língua Portuguesa, respeitando duas grandes estudiosas: Kleiman (1998) e Soares (1998), que definem 'Letramento' e justificam sua escolha apoiandose em seu significado, ou seja: "resultado da ação de ensinar ou aprender a ler e escrever: estado ou condição que adquire um grupo social ou um indivíduo como consequência de ter-se apropriado da escrita" (KLEIMAN; SOARES, 1998, p. 18). Ainda nesta perspectiva, Kleiman (1998, p. 19) apud Sasseron; Carvalho (2011, p. 60- 
61) apresenta uma definição para o conceito em virtude da complexidade. Propõe significação como "conjunto de práticas sociais que usam a escrita enquanto sistema simbólico e enquanto tecnologia, em contextos específicos para objetivos específicos".

Devido à variedade semântica, neste estudo utilizamos a expressão Alfabetização Científica, proposto por Chassot (2016):

'Alfabetização Científica' como o conjunto de conhecimentos que facilitam aos homens e mulheres fazer uma leitura de mundo onde vivem. Seria desejável que alfabetizados cientificamente, não apenas tivessem facilidade à leitura do mundo onde vivem, mas entendessem a necessidade de transformá-lo, e transformá-lo para melhor. (CHASSOT, 2016, p. 70).

O termo circunscreve a proposta do grupo de pesquisa do Núcleo Interdisciplinar de Estudos e Pesquisas em Ciência, Tecnologia e Sociedade (NIEPCTS), da Universidade Cruzeiro do Sul, pois a Alfabetização Científica (AC) é um dos temas contemplados pela abordagem Ciência/Tecnologia/Sociedade (CTS) na Educação em Ciências.

Muito há para se discutir sobre Alfabetização Científica. Teóricos do mundo das Ciências têm promovido debates acerca da temática com o seguinte argumento: o educando, não importando sua idade cronológica, deve ser inserido no contexto do conhecimento científico.

Cabe ressaltar que existem outros espaços para a comunicação da Alfabetização Científica, produzidos pelas experiências individuais dos estudantes e do grupo social a que pertencem, já que a leitura que se faz do mundo não se limita ao espaço da unidade escolar, mas envolve todo o entorno de sua existência. 


\section{METODOLOGIA DE PESQUISA}

Este estudo caracteriza-se como pesquisa qualitativa do tipo "estado do conhecimento", definida como um gênero bibliográfico que permite o mapeamento das produções científicas em diferentes campos do conhecimento, uma vez que antecede o estudo em andamento sobre concepções de Alfabetização Científica. O estado do conhecimento, pelo seu caráter bibliográfico, possibilita o mapeamento das produções acadêmicas em diversas áreas de conhecimento, buscando verificar certas concepções em tempos e espaços e situações de produção de dissertações de mestrado, teses de doutorado, artigos científicos oriundos de eventos acadêmicos (FERREIRA, 2016). Com as dissertações mapeadas, buscou-se identificar quais caminhos metodológicos foram utilizados e quais os públicos-alvos dessas pesquisas que apresentaram como relevância a temática AC.

Esta busca foi realizada em janeiro de 2018 em dissertações publicadas em âmbito nacional durante o segundo semestre de 2017 e ao longo de 2018. Com o intuito de fomentar os dados deste estudo, foram utilizadas as publicações veiculadas nos seguintes nichos: Biblioteca Digital Brasileira de Teses e Dissertações (BDTD), Scientific Electronic Library Online (SCIELO Brasil), Banco de Teses da CAPES/Cnpq.

Para sistematizar e analisar os dados obtidos, os resumos foram classificados e analisados com o emprego da técnica Análise de Conteúdo, proposta por Bardin (2016). Segundo a autora, a análise de conteúdo é constituída por diferentes momentos e é organizada em três etapas: pré-análise, exploração do material e tratamento dos resultados, inferência e interpretação.

Na pré-análise utilizamos os repositórios da BDTD a partir do descritor Alfabetização Científica. Estando próximo ao procurado, partiu-se para análise dos resumos das dissertações encontradas nos programas de Ensino de Ciências, com objetivos claros em relação aos termos produzidos no período de 2013 a 2017. Na etapa de exploração do material, definiu-se a unidade de análise Alfabetização Científica na Educação Básica e no Ensino Superior, e duas categorias: o público-alvo (alunos, 
professor e outros) e as metodologias utilizadas nas pesquisas sobre Alfabetização Científica.

$\mathrm{Na}$ terceira etapa, de tratamento dos resultados, inferência e interpretação, foi construída um quadro para a sistematização das informações, contendo o panorama de dados como: ano da defesa, título, autor, instituição, programa de pós-graduação, metodologia, instrumentos de coleta de dados e público alvo.

\section{RESULTADOS E ANÁLISES}

No sentido de ordenar as produções mapeadas, em um total de 25 dissertações pesquisadas no período de 2013 a 2017, foi produzido um quadro matriz, a fim de contribuir para reflexões acerca da unidade de análise e suas categorias. Neste quadro, apresentamos um panorama das pesquisas acadêmicas: ano, título, autor, instituição, programa, metodologia, instrumento de coleta de dados e público alvo.

Partindo do panorama exposto, e de acordo com objetivo deste artigo, foi produzido um quadro que apresenta as metodologias utilizadas nas dissertações pesquisadas. Vale ressaltar que durante o processo, foram encontradas dissertações em outros programas de pós-graduação, no entanto, atemo-nos apenas aos programas de ensino de Ciências, a saber: Ciências e Matemática, Ciências e Tecnologia e Ciências Naturais, pois são estes programas que atendem nossa pesquisa.

Para a identificação das metodologias, buscou-se a leitura dos resumos - em alguns casos houve a necessidade de adentrarmos em capítulos específicos das dissertações, para melhor compreensão do caminho metodológico, isto é, para uma análise meticulosa dos instrumentos de coleta de dados, entre outros fragmentos do trabalho investigativo do autor.

É sabido que a escolha da metodologia segue parâmetros. Segundo Gil (2002, p. 41), "toda e qualquer classificação se faz mediante algum critério. Com relação às pesquisas, é usual a classificação com base em seus objetivos gerais". Neste sentido, 
a exploração feita nas dissertações demostrou que a escolha das metodologias sustentou-se nos objetivos das consultas.

Os autores buscaram nas suas práticas o entendimento da análise dos dados coletados. Segundo Barros e Lehfeld (2007, p. 105), "A coleta de dados é a fase da pesquisa que se indaga a realidade e se obtém dados pela aplicação de técnicas". No processo de investigação, pode-se observar que estas técnicas seguem o que propõe Severino (2007), ou seja, são condutas que auxiliaram na produção da pesquisa, sendo utilizadas em diferentes estudos, em diferentes pesquisas, segundo as diferentes metodologias. Estas devem estar em consonância com os métodos adotados e os paradigmas epistemológicos propostos na pesquisa.

A temática Alfabetização Científica favorece uma abertura heterogênea de abordagens metodológicas, permitindo ao pesquisador utilizar diferentes estratégias para coletar dados. Nas dissertações analisadas, foram utilizadas estratégias como: Sequência de Ensino Investigativo, Análise dos Indicadores de Alfabetização Científica e Eixos Estruturantes, identificação de fala e texto dos alunos, Análise Interacional, análise das explicações da qualidade conceitual, atividades escritas, atividades artísticas e ações desenvolvidas pelos alunos, registros de imagens por meio de fotografias, registros em fichas preenchidas pelos alunos partindo de uma sequência didática, questionário, descrição, análise de dados, observação, transcrição da produção oral, discussões, pesquisas bibliográficas, elaboração e análise de mapas conceituais, fotos e desenhos, protocolo de observação participante, gravações em áudio, transcrições e fotografias, questionário com perguntas abertas e fechadas, entrevista semiestruturada, observação participante (como os registros no roteiro de um museu), produção textual e conversas informais, observação direta, registro de fotos e pintura, predominância descritiva, observação participante, atividades e relatos de atividades, observações do pesquisador.

Vale destacar a presença expressiva de questionários, sempre aplicados por contato direto, evidenciando a segurança que o pesquisador proporciona durante o processo, uma vez que o mesmo deve orientar ou resolver qualquer impasse surgido durante a realização da pesquisa de campo. Observou-se, também, que os questionários eram 
utilizados com outros instrumentos, aproximando de forma mais contundente os resultados dos objetivos propostos nos estudos.

Em relação à diversidade dos instrumentos encontrados nas pesquisas analisadas, ressaltamos que três dissertações utilizaram apenas um instrumento. Logo, podemos destacar que vinte e duas (22), do total de vinte e cinco (25), utilizou-se de dois ou mais instrumentos, isto demostra as possibilidades de investigação no tocante à Alfabetização Científica (AC) nos diversos Programas de Ensino de Ciências.

$\mathrm{Na}$ categoria público-alvo, umas das unidades de registro foram os professores. Encontramos docentes dos níveis da Educação Básica, totalizando seis (6) professores, distribuídos em: Ensino Fundamental I e II e Ensino Médio. Não foram encontradas pesquisas com professores do Ensino Superior. Apenas uma pesquisa foi identificada tendo como foco a Formação Continuada para professores pedagogos, objetivando contribuir com o repertório científico deste grupo de educadores. Segundo a autora, a formação continuada possibilita o desenvolvimento do conhecimento científico na temática proposta na pesquisa "Resíduo Sólido". Houve a participação de especialistas, oficinas e visitas, que contribuíram para a reflexão sobre a prática pedagógica. As atividades propostas trouxeram uma possibilidade de mudança nos currículos, com o intento de trabalhar a Alfabetização Cientifica desde os primeiros anos do Ensino Fundamental (SILVA, 2017).

Em relação aos trabalhos com professores do Ensino Fundamental II, encontramos apenas uma pesquisa com professores e alunos de classes especiais, com ênfase nos discentes. Realizou-se um diagnóstico prévio com os docentes a fim de identificar as possibilidades e desafios da educação inclusiva, observando o perfil desses professores, as concepções que os mesmos possuíam e as adversidades encontradas. Ouvir os professores de classes inclusivas, conhecer seus anseios, foi importante, visto que a maioria destes profissionais não possuem formação específica para trabalhar com alunos inclusos, o que se revela como problema em relação a certas dificuldades apontadas pelos professores no decorrer da pesquisa. Desta forma, cabe aos dirigentes da educação lançar recursos para que estas demandas sejam atenuadas (VIER, 2016). 
Em relação aos professores do Ensino Médio, foram encontradas quatro (4) pesquisas das quais uma (1) foi realizada com professores de escolas técnicas participantes do curso de formação do PARFOR (Plano Nacional de Formação dos Professores da Educação Básica), curso este oferecido pela Universidade Tecnológica Federal do Paraná (UTFPR), que tem como objetivo a atualização profissional dos educadores no que concerne à licenciatura, já que estes profissionais possuem formação técnica. Nas outras três pesquisas temos dois professores participantes dos grupos de pesquisa "Linguagem e Ensino de Ciências (LINCE)", e um participante do Laboratório de Pesquisa e Ensino de Física (LaPEF), ambos pertencentes à Universidade de São Paulo (USP). Estes dois grupos têm como proposta pesquisas relacionadas ao Ensino da Linguagem Científica (LINCE) e os conceitos de Física, vinculados ao fazer científico e sua relação com a sociedade (LaPEF).

Ainda no Ensino Médio foram encontradas pesquisas com alunos da Educação de Jovens e Adultos (EJA), tratando de conceitos de Genética, demostrando como os educandos desta modalidade de ensino, quando empoderados das questões Ciências, Tecnologia e Sociedade, desenvolvem-se e tornam-se críticos em relação às questões que envolvem o desenvolvimento social do qual fazem parte (SALES, 2013).

No Ensino Médio regular, as pesquisas com alunos do primeiro ano abordaram o conteúdo dinâmica populacional, com aplicação de uma Sequência de Ensino Investigativo (SEI), com o propósito de desenvolvimento da argumentação, através de eixos estruturantes elaborados pelos grupos de pesquisa LINCE e LaPEF, da USP, como parâmetros para a Alfabetização Científica.

Ainda no Ensino Médio regular, alunos do terceiro ano participaram de uma pesquisa, em aulas de química, com saberes populares, sob o enfoque CTS no conteúdo funções orgânicas. Já em outra dissertação, os pesquisados, também alunos do terceiro ano, nas aulas de física, utilizaram o conteúdo dualidade, com foco em onda, partícula e luz, com o propósito de mapear quais os instrumentos são utilizados pelo professor a fim de promover a argumentação nos estudantes com o enfoque ensino 
por investigação para o desenvolvimento da AC. Não foram encontradas dissertações com estudantes do $2^{\circ}$ ano.

Nas pesquisas referentes ao público alunos do Ensino Superior, foram encontrados apenas três trabalhos, com duas dissertações com discentes de Licenciatura em Química. Em uma delas, o objetivo era investigar o conceito de AC manifestado pelos discentes, na qual os resultados revelaram que a visão da temática aproxima-se da tendência construtivista com abordagem CTS, porém a prática ainda está relacionada ao ensino tradicional (ARAGÃO, 2014). Na segunda pesquisa do mesmo Curso de Licenciatura em Química, o objetivo foi investigar a influência de ações de Alfabetização Científica na formação inicial a partir da construção participativa de um Museu Itinerante de Química (MIQ). O resultado desta pesquisa foi considerado satisfatório, pois os licenciados respaldaram-se em teorias sobre AC, o que trouxe aos futuros educadores a percepção da relevância da Educação Científica direcionada para o contexto escolar, por terem sidos impelidos a aprender e a ensinar por meio da pesquisa (SILVA, 2017).

Neste grupo, encontramos uma dissertação curiosa e estimulante, abordando um fato único, uma averiguação com alunos de Licenciatura do curso de Física e alunos do curso de Artes Visuais. O objetivo foi sugerir uma proposta de alfabetização visual e científica que propiciasse a leitura e a análise de representações astronômicas em espaços interdisciplinares, que favorecessem as áreas de Artes Visuais e Física. Nesta pesquisa, a proposta baseava-se em leitura de imagens astronômicas para a reflexão e leitura crítica e científica com os dois grupos de estudantes. Os resultados demostraram que a Alfabetização Científica com alunos dos dois cursos promoveram mudanças de atitudes e de concepções, na passagem e transformação do senso comum em conhecimento científico. Isto ocorreu graças ao embasamento teórico e, sobretudo, às práticas desenvolvidas durante a pesquisa, demostrando que as atividades aconteceram em uma proposta teórica e prática interdisciplinar, o que sugere um novo olhar e um novo fazer pedagógico (MARTINS NETO, 2016).

Acreditamos que, mesmo as instituições com os programas de Ensino de Ciências cujo tema pesquisado, demostrou que algumas regiões do país ainda precisam 
despertar o interesse pelo eixo Ciência/Tecnologia/Sociedade e, consequentemente, a Alfabetização Científica, visto que a temática está presente na Base Nacional Comum Curricular. Os profissionais da Educação Básica e do Ensino Superior devem motivar-se na busca por informações e, como consequência, a adesão aos programas acontecerá de forma crescente, já que urge a necessidade do enculturamento científico para a formação da cidadania.

\section{CONSIDERAÇÕES FINAIS}

O estudo aqui apresentado permitiu o levantamento e a análise de vinte e cinco (25) pesquisas acadêmicas em que foi possível identificar a Alfabetização Científica como tema e as respectivas metodologias utilizadas, quais sujeitos participaram da investigação, quais os programas de Pós-Graduação em Ensino de Ciências.

O tema Alfabetização Científica identificado nas dissertações analisadas foi desenvolvido a partir de referencial teórico brasileiro, o que já representa um avanço do tema no país. São autores que divulgam suas práticas sobre o tema, considerado relevante para a Educação Brasileira e para outros países da América do Sul (SANTOS; AMARAL; MACIEL, 2010; SASSERON; CARVALHO 2011; VIECHENESKI; CARLETTO, 2011; CABRAL, 2014; CHASSOT, 2016, entre outros). Sob o ponto de vista destes autores, a Alfabetização Científica como uma compreensão de ensino para a formação de um cidadão crítico, capaz de inserir-se no conhecimento científico, desenvolve nos estudantes habilidades para argumentações fundamentadas em teorias que vão ajudá-lo a decidir e a emitir opiniões acerca dos fenômenos naturais ou em um contexto de mau uso ambiental.

Esta pesquisa evidenciou que a diversidade metodológica encontrada nas dissertações desenvolvidas em instituições de pesquisas acadêmicas brasileiras, no período de 2013 a 2017, comprova que o tema Alfabetização Científica é um tema atual e faz parte da tendência das pesquisas em Ciência, Tecnologia e Sociedade; que as demandas impostas pelas situações dos impactos provenientes da ciência e tecnologia são motivos de pesquisa na Educação Básica e no Ensino Superior. As metodologias utilizadas promoveram a possibilidade de uma pluralidade de coletas de 
dados, o que pôde gerar discussões ricas, evidenciando a necessidade da inserção do tema desde os primeiros anos do Ensino Fundamental, bem como na formação inicial e continuada de professores.

Esperamos que as análises realizadas possam contribuir para que outros pesquisadores da área de Ensino de Ciências e áreas afins possam ressignificar suas práticas e despertar o interesse de outros estudiosos, incentivando novas buscas, ampliando o entendimento, aumentando as potencialidades e diminuindo as limitações. Será, portanto, possível revelar a importância e o interesse de educadores da Educação Básica e do Ensino Superior para o desenvolvimento de práticas sobre Alfabetização Científica, objetivando a formação de estudantes cientificamente alfabetizados e capazes de envolver-se em discussões embasados nos conhecimentos científicos e tecnológicos.

\section{REFERÊNCIAS}

ARAGÃO, Suzana Bruna Carneiro. Alfabetização Científica: concepções dos futuros professores de química. Dissertação (Mestrado em Ensino de Ciências). Universidade de São Paulo. São Paulo, 2014.

BARDIN, Lurence. Análise de conteúdo. 70. Ed. São Paulo: Almedina Brasil, 2016.

BARROS, Aidil de Jesus Pais de; LEHFELD, Neide Aparecida de Souza. Fundamentos da metodologia científica. 3. ed. São Paulo: Pearson Prentice Hall. 2007.

BRASIL. Ministério da Educação. Lei de Diretrizes e Bases da Educação Nacional (Lei 9.394/96). Brasília: MEC, 1996. Disponível em: http://portal.mec.gov.br.pdf. Acesso em: 20/10/2018.

. Ministério da Educação. Base Nacional Comum Curricular. 2017. Disponível em: http://basenacionalcomum.mec.gov.br/. Acesso em: 05/06/2017. 
. Secretaria de Ensino Fundamental. In: Parâmetros Curriculares Nacionais. Brasília, MEC, 1997.

CABRAL, Sonia Aparecida; SEPINI, Ricardo Pereira; MACIEL, Maria Delourdes. Alfabetização científica e o ensino de Ciências. Congresso lbero-Americano de Ciências, Tecnologia, Inovação e Educação, Buenos Aires. Anais. Buenos Aires, 2014. Acesso em 21/02/2018.

CARVALHO, Anna Maria Pessoa de. Formação de professores de ciências: tendências e inovação. 10 ed. São Paulo: Cortez, 2011.

CHASSOT, Attico. Alfabetização científica: questões e desafios para a educação. ljuí: Unijuí, 2016.

CUNHA, Maria Borin da. O movimento ciência/tecnologia/sociedade (CTS) e o ensino de Ciências: condicionantes estruturais. In: Varia scientia, 6 (12), 121-134. Disponível em: Unioeste/Br.Index/php/. 2006. Acesso em: 12/11/2017.

FERREIRA, Norma Sandra de Almeida. As pesquisas denominadas estado da arte. In: Educação \& Sociedade. 23(79), 257-272, 2016. Disponível em: http://www.scielo.br/pdf/es/v23n79/10857.pdf. Acesso em: 30/01/2018.

GIL, Antônio Carlos. Como elaborar projetos de pesquisa. 4 ed. São Paulo: Atlas, 2002.

KLEIMAN, Angela Bustos. Modelos de Letramento e as Práticas de Alfabetização na Escola, In: KLEIMAN, A. B. (org.). In: Os Significados do Letramento: uma nova perspectiva sobre a prática social da escrita, Campinas: Mercado das Letras, 1998.

KRASILCHIK, Myriam. Reformas e realidade: o caso do ensino das Ciências. In: São Paulo em Perspectiva. 1(14). 2000. Disponível em: http://www.scielo.br/pdf/spp/v14n1/9805. Acesso: 19/04/2017.

LOPES, Wener Zacarias; JESUS, Rhenan Ferraz de; FOLMER, Vanderlei; PUNTE, Robson Luiz. Concepções de professores dos anos iniciais sobre a Alfabetização 
Científica (AC) e a abordagem Ciência, Tecnologia e Sociedade (CTS) no ensino de Ciências. In: Revista Ciências e Ideias. 8 (1), 1-22. 2017.

MARTINS NETO, Luzita Erichsen. Alfabetização visual e científica: aproximações a partir de temas da Astronomia. Dissertação de mestrado, Universidade Tecnológica Federal do Paraná, Ponta Grossa, PR, Brasil 2016. Disponível em: http://repositorio.utfpr.edu.br/jspui/bitstream/1/1965/1/PG. Acesso em: 30/10/2017.

SANTOS Mirian Stassum dos; AMARAL, Carmem Lucia Costa; MACIEL, Maria Delourdes. Temas sociocientíficos em aulas práticas de Química na Educação Profissional: uma abordagem CTS. In: MACIEL, Maria Delourdes; AMARAL, Carmem Lúcia Costa; GUAZZELLI lara Regina Bocchese. (Orgs). Ciência, Tecnologia e Sociedade: pesquisa e ensino. São Paulo: Terracota, pp. 165-178, 2010.

SASSERON, Lúcia Helena; CARVALHO, Anna Maria Pessoa de. Alfabetização científica: uma revisão bibliográfica. In: Investigações em Ensino de Ciências. 16(1), 59-77. 2011. Disponível em: https://edisciplinas.usp.br/pluginfile.php/844768. Acesso em: 22/11/2018.

SEVERINO, Antônio Joaquim. Metodologia do trabalho científico. 23 ed. São Paulo: Cortez, 2007.

SILVA, Idione. Formação Continuada de Professores Sobre Gestão de Resíduos Sólidos: uma proposta para alfabetização científica nos anos iniciais. Dissertação Programa de Pós-Graduação em Ensino de Ciências Naturais e Matemática, Universidade Regional de Blumenal, 2017. Disponível em: http://www.bc.furb.br/docs/DS/2017/362606_1_1.pdf. Acesso em: 05/01/2018.

SILVA, Mirian Pacheco; ALBRECHT, Evonir. A Formação de professores sob o enfoque da Ciência, Tecnologia e Sociedade, Ciências, Tecnologia e Sociedade. In: MACIEL, M.; AMARAL, C.; GUAZZELLI, I. (Orgs). Ciência, Tecnologia e Sociedade: pesquisa e ensino. São Paulo: Terracota, 2010. 
SOARES, Magda. Letramento: um tema em três gêneros, Belo Horizonte: Autêntica. 1998.

SOLIGO, Marina Guazzelli; MACIEL, Maria Delourdes; GUAZZELLI, lara Regina Bocchese. Importância de se levar em consideração as interações de alunos adolescentes com a mídia televisiva e redes sociais para uma proposta de ACT de cunho CTS. In: Revista de Ensino de Ciências e Matemática, 3 (3), 269-281, 2010.

TRIVELATO, Silvia Frateschi; SILVA, Rosana Ferreira. O Ensino de Ciências. ed. São Paulo: CENGAGE Learning. 2011.

VIECHENESKI, Juliana Pinto; CARLETTO, Márcia Regina. Ensino de Ciências e Alfabetização Científica nos anos iniciais do Ensino Fundamental: um olhar sobre as escolas públicas de Carambeí. In: Anais VIII ENPEC: Encontro Nacional de Pesquisa em Educação em Ciências e I CIEC - Congreso Iberoamericano de Investigación en Enseñanza de las Ciencias, 2011, Campinas, 2011.

VIEIRA, Rui Marques; MARTINS, Isabel Pereira. Práticas de Professores do Ensino Básico Orientadas numa Perspectiva CTS-PC. Revista CTS, p.79-86. 2009.

VIER, Rejane Fernandes da Silva. Práticas pedagógicas inclusivas com enfoque CTS para alunos público-alvo da educação especial. Dissertação de mestrado, Universidade Tecnológica Federal do Paraná, Ponta Grossa, PR, 2016.

Enviado: Março, 2019.

Aprovado: Março, 2019. 